\title{
Anodic Determination of Acetylsalicylic Acid at a Mildly Oxidized Boron-Doped Diamond Electrode in Sodium Sulphate Medium
}

\author{
Codruţa Cofan ${ }^{1}$ and Ciprian Radovan ${ }^{2}$ \\ ${ }^{1}$ Department of Chemistry, School of Pharmacy, University of Medicine and Pharmacy "Victor Babes" Timisoara, Piata E. Murgu, \\ no. 2, 300041 Timisoara, Romania \\ ${ }^{2}$ Laboratory of Electrochemistry, West University of Timisoara, Pestalozzi Street, no. 16, 300115 Timisoara, Romania
}

Correspondence should be addressed to Codruţa Cofan, cofancodruta@umft.ro

Received 11 March 2011; Accepted 6 April 2011

Academic Editor: Bengi Uslu

Copyright ( 2011 C. Cofan and C. Radovan. This is an open access article distributed under the Creative Commons Attribution License, which permits unrestricted use, distribution, and reproduction in any medium, provided the original work is properly cited.

Differential pulse voltammetry (DPV) and chronoamperometry (CA) were used to detect and determine acetylsalicylic acid (ASA) at a mildly oxidized boron-doped diamond (BDD) electrode in a neutral sodium sulphate solution as supporting electrolyte. ASA determination in unbuffered medium was achieved using neutralized standard and real samples. Over the concentration range of $0.01 \mathrm{mM}-0.1 \mathrm{mM}$, linear calibration plots of anodic current peaks in DPV and anodic currents in CA experiments versus concentration were obtained with very high correlation coefficients and good sensitivity values. The limits of detection were situated around $1 \mu \mathrm{M}$. The association of DPV and CA techniques with standard addition method represented a suitable option for the determination of ASA in real samples such as pharmaceutical formulations.

\section{Introduction}

Acetylsalicylic acid (ASA) or aspirin, the world's oldest and best known nonsteroidal anti-inflammatory drug, continues to receive special attention due to its clinical effects on inflammation, fever, renal function, and platelet aggregation $[1,2]$. Recent studies have shown that administrated in specific dosages, aspirin has the ability to prevent cardiovascular events and different types of cancer and to reduce even the incidence of Altzheimer's disease occurence [3-5]. ASA has also an antioxidant effect. In contrast, evidence proves that it induces formation of free-radicals which are involved in gastrointestinal damage and development of gastroduodenal ulcer [6-9]. After entering the bloodstream, acetylsalicylic acid is rapidly metabolized in salicylic acid (SA), the compound known to be primarily responsible for the pharmacological activity of ASA $[1,4,10,11]$. The therapeutic action and the toxic effects of this widely consumed active substance promote ASA as a drug continuously subjected to extensive research.

A survey in the literature indicates a variety of analytical techniques used for the detection and determination of ace- tylsalicylic acid. Generally, ASA is indirectly determined after the conversion to salicylic acid, its main hydrolysis product $[4,10]$. The conventional "back-titration" method specified by British Pharmacopoeia and the Trinder reaction are methods of reference for the determination of ASA and salicylates, respectively [12-14]. In time, "back-titration" and Trinder reaction have been replaced by methods such as spectroscopy, mass spectrometry, UV-VIS spectrophotometry, spectrofluorimetry, gas chromatography, different types of liquid chromatography, and capillary electrophoresis. The latter methods, used independently or coupled with various detection modes, were applied for ASA investigation in biological fluids, pharmaceutical preparations, and even waste waters $[4,5,10,13,15,16]$. The detection and determination of aspirin using the above-mentioned techniques have been achieved in both single $[13,15,17,18]$ and multicomponent systems $[10,19-29]$.

Acting as electroactive substance through salicylic acid, aspirin's main hydrolysis product, ASA has also been electrochemically studied from a mechanistic or analytical perspective, using a range of methods, electrode types, and, supporting electrolytes [12, 30-48]. 
Boron-doped diamond (BDD) is a very important material for electroanalysis, since it exhibits several electrochemically valuable properties such as its very wide electrochemical window in aqueous solutions resulting from the high overpotentials of the oxygen and hydrogen evolution reactions, low and stable voltammetric and amperometric background current, its excellent chemical and electrochemical stability in aggressive conditions, and its good responsiveness to a range of analytes without any conventional pretreatment [49-59].

Several important studies reported the determination of ASA in pharmaceutical formulations based on its hydrolysis to salicylate at controlled temperature conditions, using unmodified or modified graphite [30, 46], carbon paste [30] and glassy carbon [32, 33, 36, 37, 39, 47] electrodes, and different supporting electrolytes, some of them having the inconvenience of methanol $[30,33,36]$, diethylether, or ethanol-diethylether [37] content.

Published data reports the use of a boron-doped diamond (BDD) electrode for the electrochemical evaluation of salicylic acid in acidic media [34]. At the same time, the voltammetric study of SA electrochemical oxidation at BDD electrode is merely presented. Mineralization of salicylic acid in acidic aqueous solution by electrochemical advanced oxidation processes using a BDD electrode as anode has also been explored [45]. Only one published paper [48] describes the determination of acetylsalicylic acid from pharmaceutical products by square-wave voltammetric data, using a specially treated boron-doped diamond electrode with very high overpotential for ASA oxidation in an $\mathrm{H}_{2} \mathrm{SO}_{4}$ medium and without a preliminary hydrolysis step.

This paper presents the cyclic voltammetry (CV) investigation and the determination of acetylsalicylic acid by anodic differential pulse voltammetry (DPV) and chronoamperometry (CA), using a stationary mildly oxidized unmodified BDDE and a very simple and easy accessible supporting electrolyte, a neutral sodium sulphate solution. The actual report continues by outlining specific applications of DPV and CA techniques explored at a BDD electrode coupled with standard addition method to the analysis of two commercialized pharmaceutical formulations.

\section{Experimental}

The electrochemical data were obtained from CV, DPV, and CA measurements. A Metrohm three-electrode cell equipped with a stabilized BDDE working electrode as a $3 \mathrm{~mm}$ diameter stationary disc embedded in a PEEK (PolyEtherEtherKetone) rod, a platinum foil counter-electrode, and a saturated calomel reference electrode (SCE), was used to perform the electrochemical measurements. The unmodified commercial boron-doped diamond electrode supplied by Windsor Scientific Ltd. for electroanalytical use was a mirror-polished doped polycrystalline industrial diamond (microcrystalline, doping degree cca. $0.1 \%$ boron) prestabilized in our laboratory by mild electrochemical oxidation at $+2 \mathrm{~V}$ versus SCE in neutral and alkaline media and several hundreds repeated alternate polarization cycles between -1 and $+2 \mathrm{~V}$ versus SCE in acidic and neutral media. All voltammograms were collected using an Autolab PGstat 20 EcoChemie system controlled by a PC running GPES Software version 4.9. The CV measurements obtained corresponded to restricted potential limits ranged between $0 \mathrm{~V}$ and $+1.25 \mathrm{~V}$ versus SCE and a scan rate between 0.005 and $0.03 \mathrm{Vs}^{-1}$, usually of $0.03 \mathrm{Vs}^{-1}$. Working parameters for the exemplified differential pulse voltammograms involved a modulation time of $0.05 \mathrm{~s}$, an interval time of $0.25 \mathrm{~s}$, an initial potential of $0 \mathrm{~V}$, an end potential of $1.25 \mathrm{~V}$, a step potential of $0.00405 \mathrm{~V}$, a modulation amplitude of $0.02502 \mathrm{~V}$, and a scan rate of $0.0162 \mathrm{Vs}^{-1}$. CVs, DPVs, and CAs were recorded at stationary electrode in quiescent solutions, in a controlled argon atmosphere, and at room temperature $\left(23 \pm 1^{\circ} \mathrm{C}\right)$.

Before starting each series of electrochemical measurements, the working electrode was carefully cleaned, degreased, and treated to remove fouling by polishing with alumina aqueous suspension, and finally thoroughly washed with double-distilled water. Each determination was repeated three times with good reproducibility of the practically stabilized state of electrode surface recovered by simple means of cleaning of the electrode, short resting period, and brief stirring of the solution between the successive measurements.

The supporting electrolyte was a $0.1 \mathrm{M} \mathrm{Na}_{2} \mathrm{SO}_{4}$ unbuffered solution, $\mathrm{pH}$ practically 7 . The substances used were analytical grade Merck reagents. Acetylsalicylic acid standard solutions were freshly prepared at room temperature $(23 \pm$ $1^{\circ} \mathrm{C}$ ), by addition of an $\mathrm{NaOH}$ diluted solution in order to transform the target substance into freely water-soluble salt. The explored concentrations of ASA for determination of a coherent electroanalytical method ranged between 0.01 and $0.1 \mathrm{mM}$ in DPV exploration and between 0.01 and $0.09 \mathrm{mM}$ in CA experiments. The higher investigated concentration ranges had no relevance for electroanalytical purpose, and a distinct access to a low limit of detection is being desirable.

The electroanalytical application of DPV and CA methods associated with standard addition method for detection and determination of acetylsalicylic acid was verified using Aspirin tablets (BAYER) and Acid Acetilsalicilic tablets (SICOMED). The real samples from pharmaceutical formulations were aqueous solutions freshly prepared by dissolution of Aspirin tablets and Acid Acetilsalicilic tablets, respectively. $250 \mathrm{~mL}$ as stock solutions were made up from a single Aspirin or Acid Acetilsalicilic tablet, under similar conditions as standard solutions. Very small volumes of the standard solutions were added to obtain the desired additional concentrations while maintaining a practically constant solution volume in the cell. The final working solution volume in the cell was $50 \mathrm{~mL}$. All the dilutions of the investigated standard and real sample solutions were made using the simple, easy accessible, unbuffered sodium sulphate supporting electrolyte.

\section{Results and Discussion}

A series of cyclic voltammetry data recorded in a neutral unbuffered sodium sulphate solution used as supporting 


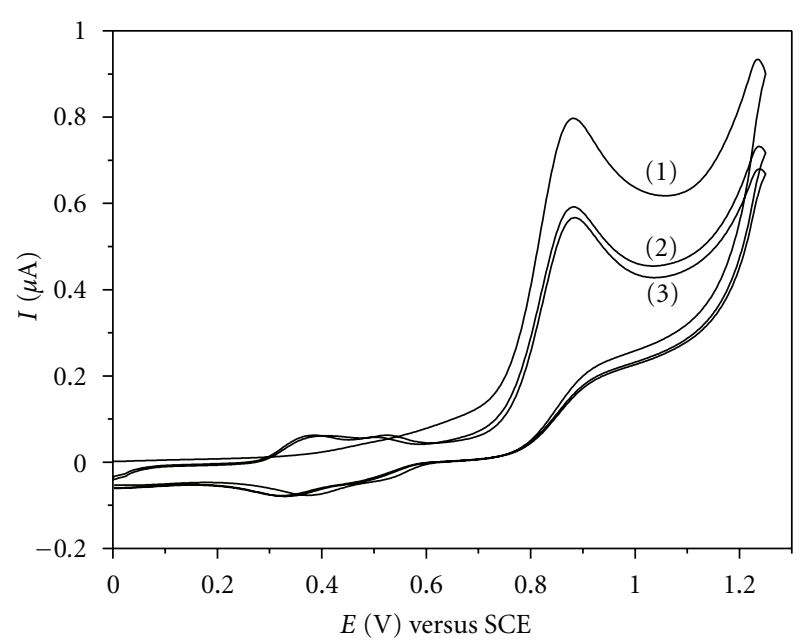

Figure 1: Cyclic voltammograms of $0.03 \mathrm{mM}$ ASA. Supporting electrolyte: $0.1 \mathrm{M} \mathrm{Na}_{2} \mathrm{SO}_{4} \mathrm{pH} 7$; starting potential: $0 \mathrm{~V}$ versus SCE; potential range: $0 \mathrm{~V} \rightarrow+1.25 \mathrm{~V} \rightarrow 0 \mathrm{~V}$ versus SCE; scan rate: $0.03 \mathrm{Vs}^{-1}$; (1)-(3): scan 1-scan 3.

electrolyte represented the starting point in evaluating the electrochemical behavior of ASA at an unmodified BDDE. Figure 1 depicts typical examples of anodic cyclic voltammetric responses corresponding to electrochemical oxidation of $0.03 \mathrm{mM}$ ASA at an unmodified BDDE in a neutral $0.1 \mathrm{M}$ $\mathrm{Na}_{2} \mathrm{SO}_{4}$ solution. The CV successive scans were collected in the potential range between $0 \mathrm{~V}$ versus SCE and $+1.25 \mathrm{~V}$ versus SCE, starting in the positive direction from $0 \mathrm{~V}$ versus SCE, at a scan rate of $0.03 \mathrm{Vs}^{-1}$. On the forward branch of the first scan, a well-defined anodic current peak attributable to anodic oxidation of ASA disposed around $+0.9 \mathrm{~V}$ versus SCE.

The practical overlapping of second and third scans disposed below the first one corresponded to a stationary state of diffusively controlled anodic process. Voltammograms for ASA solutions, with anodic and cathodic branches (obtained but not presented here in the figures), corresponded to an irreversible electrochemical behavior of the studied compound at an unmodified BDDE. Our work relates only to the analytically oriented investigations without any consideration of the mechanistic aspects.

The influence of the scan rate on ASA anodic oxidation at BDDE in unbuffered $0.1 \mathrm{M} \mathrm{Na}_{2} \mathrm{SO}_{4}$ solution ( $\mathrm{pH}$ 7) has been investigated for $0.03 \mathrm{mM}$ ASA final concentration in the electrochemical cell, under cyclic voltammetric conditions. CV scans (see Figure 2) initiated by potential sweep in the positive direction starting from $0 \mathrm{~V}$ versus SCE were recorded for scan rates between 0.005 and $0.03 \mathrm{Vs}^{-1}$. A progressive increase of current peaks manifested around +0.9 V versus SCE and corresponding to ASA anodic oxidation was remarked while increasing scan rate.

The diffusively controlled anodic oxidation process of ASA at BDDE and the absence of adsorbed reaction products on electrode surface were confirmed by the linear dependency and zero intercept of anodic current peak, $I$, versus

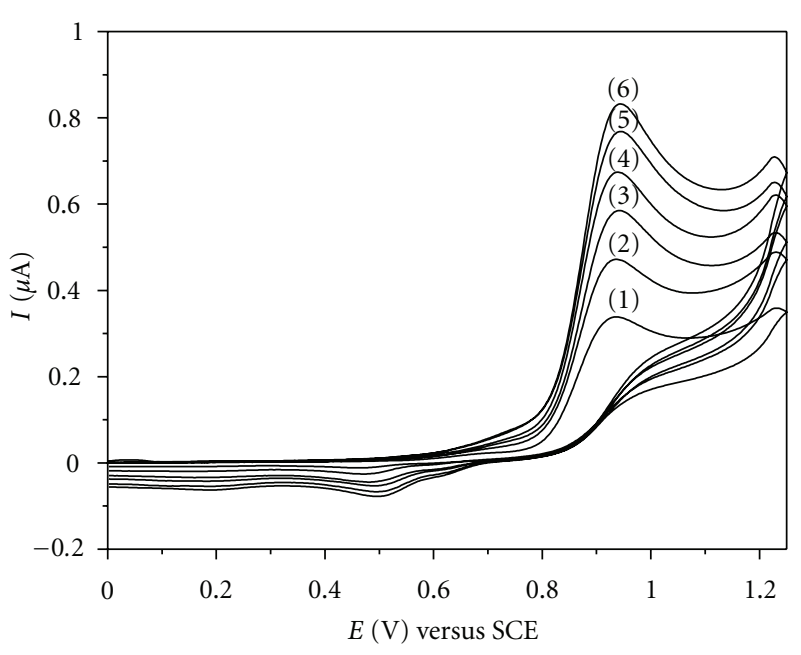

Figure 2: Cyclic voltammograms of $0.03 \mathrm{mM}$ ASA. Effect of scan rate: (1) $0.005 \mathrm{Vs}^{-1}$, (2) $0.01 \mathrm{Vs}^{-1}$, (3) $0.015 \mathrm{Vs}^{-1}$, (4) $0.02 \mathrm{Vs}^{-1}$, (5) $0.025 \mathrm{Vs}^{-1}$, (6) $0.03 \mathrm{Vs}^{-1}$; supporting electrolyte: $0.1 \mathrm{M} \mathrm{Na}_{2} \mathrm{SO}_{4} \mathrm{pH}$ 7; starting potential: $0 \mathrm{~V}$ versus SCE; potential range: $0 \mathrm{~V} \rightarrow+1.25 \mathrm{~V}$ $\rightarrow 0 \mathrm{~V}$ versus SCE.

square root of scan rate, $v^{1 / 2}\left(I=4.82 v^{1 / 2}\right.$, where $I(\mu \mathrm{A})$, $\left.v\left(\mathrm{Vs}^{-1}\right)\right)$ obtained with very good values of determination parameter $\left(R^{2}=0.999\right)$.

In addition, besides the good reproducibility and the detailed aspect regarding the control of anodic process by diffusion, the less positive potential of current peaks comparatively with literature data obtained at a strong oxidized BDD electrode [48] can be mentioned.

ASA concentration effect (not presented here) on the optimum anodic response in CV exploration at an unmodified BDDE using a neutral sodium sulphate solution as supporting electrolyte was also evaluated. The series of CVs obtained for ASA standard solution were recorded over the concentration range of $0.01 \mathrm{mM}-0.08 \mathrm{mM}$. Calibration plot data of anodic current peaks versus concentration of ASA exhibited good linearity and sensitivity (see Table 1). LOD value of $1.02 \mu \mathrm{M}$ has been calculated according to $3 \sigma /$ slope criterion, where $\sigma$ was estimated as the standard deviation applied to the net amperometric signal measured for the lowest analyte concentration corresponding to calibration plot and RSD ranged between 2 and 3\%.

After this preliminary discussion of cyclic voltammetry data, and confirmation of a diffusely controlled anodic process, more detailed investigations with electroanalytical application purposes were conducted using two other different techniques, differential pulse voltammetry, and chronoamperometry.

3.1. Differential Pulse Voltammetry Data. A series of anodic DPVs presented in Figure 3 involving ASA concentration effect at an unmodified BDDE in a $0.1 \mathrm{M} \mathrm{Na}_{2} \mathrm{SO}_{4}(\mathrm{pH}$ 7) supporting electrolyte were recorded over the concentration range of $0.01 \mathrm{mM}-0.1 \mathrm{mM}$ and using ASA standard solution.

Under conditions of the applied parameters of differential pulse voltammetry technique, sharp and well-defined 
TABLE 1: Parameters of calibration plots $\left(I=a C+b ; I(\mu \mathrm{A}) ; a\left(\mu \mathrm{AmM}^{-1}\right) ; C(\mathrm{mM}) ; b(\mu \mathrm{A})\right)$, determination coefficient, and LOD values for acetylsalicylic acid (ASA) determination using CV, DPV, and CA methods.

\begin{tabular}{lcccccc}
\hline Figure & Method & Concentration range $(\mathrm{mM})$ & Regression equation of linear calibration plot & Sensitivity $\left(\mu \mathrm{A} \mathrm{mM} \mathrm{m}^{-1}\right)$ & $R^{2}$ & $\mathrm{LOD}(\mu \mathrm{M})$ \\
\hline- & CV & $0.01-0.08$ & $I=24.175 C+0.039$ & 24.175 & 0.998 & 1.02 \\
Figure 3 & DPV & $0.01-0.1$ & $I=12.86 C+0.041$ & 12.86 & 0.998 & 1.03 \\
Figure 5 & CA & $0.01-0.09$ & $I=5.684 C-0.009$ & 5.684 & 0.997 & 1.03 \\
Figure 6 & CA $^{\mathrm{a}}$ & $0.01-0.08$ & $I=21.397 C+0.034$ & 21.397 & 0.998 & 1.08 \\
\hline
\end{tabular}

${ }^{a}$ Continuous addition, stirred solution.

current peaks corresponding to ASA oxidation manifested around $+0.9 \mathrm{~V}$ versus SCE.

Calibration plot (for calibration data, see Table 1) of anodic current peak, $I$, versus ASA concentration showed a satisfactory high sensitivity of $12.86 \mu \mathrm{AmM}^{-1}$ and a very good linearity with a determination coefficient, $R^{2}=0.998$. LOD value of $1.03 \mu \mathrm{M}$, very close to that one obtained when using CV technique, was calculated according to the same $3 \sigma /$ slope criterion previously mentioned.

The potential usefulness of DPV method at the determination of ASA content in real sample solutions was verified using aqueous solutions from tablets of Aspirin (BAYER) and Acid Acetilsalicilic (SICOMED), respectively.

Figure 4(a) depicts a series of DPVs as an example involving ASA determination in an Aspirin real sample solution. The exemplified tested real sample was prepared under the conditions mentioned in the experimental part and using a $0.5953 \mathrm{~g}$ Aspirin tablet. $0.2 \mathrm{~mL}$ Aspirin initial solution was diluted to $50 \mathrm{~mL}$ final volume in $0.1 \mathrm{M} \mathrm{Na}_{2} \mathrm{SO}_{4}(\mathrm{pH}$ 7) supporting electrolyte (0.2/50 dilution), and very small volumes of ASA standard solution were then added. ASA final supplementary concentrations in the tested real sample were $0.01 \mathrm{mM}$ and $0.02 \mathrm{mM}$, respectively. Value of $473.9 \mathrm{mg}$ ASA/tablet represented the average content determined using anodic DPV technique at BDDE associated with standard addition method. The investigation of 5 Aspirin tablets with an average weight of $0.5946 \mathrm{~g}$ led to a value of $471.2 \mathrm{mg}$ ASA/tablet. According to the general BAYER product specification, each single tablet should contain $500 \mathrm{mg}$ ASA.

A similar evaluation, Figure 4(b), corresponding to ASA determination was conducted using an aqueous real sample prepared from a $0.5925 \mathrm{~g}$ Acid Acetilsalicilic tablet. Practical results following application of DPV associated with standard addition method gave a content of $477.1 \mathrm{mg}$ ASA/tablet. An average content of $472.2 \mathrm{mg}$ ASA/tablet was obtained when investigating 5 Acid Acetilsalicilic tablets with $0.5917 \mathrm{~g}$ average weight. ASA content value in Acid Acetilsalicilic tablets indicated by the SICOMED supplier was $500 \mathrm{mg} /$ tablet.

The matrix effects, which can be attributed to particular ingredients present in the tablets, were insignificant in their impact on quantitative evaluation of ASA in real samples.

3.2. Chronoamperometry Data. The preliminary evaluation of cyclic voltammetric data for the detection and determination of acetylsalicylic acid at an unmodified BDDE using as supporting electrolyte a neutral unbuffered sodium sulphate

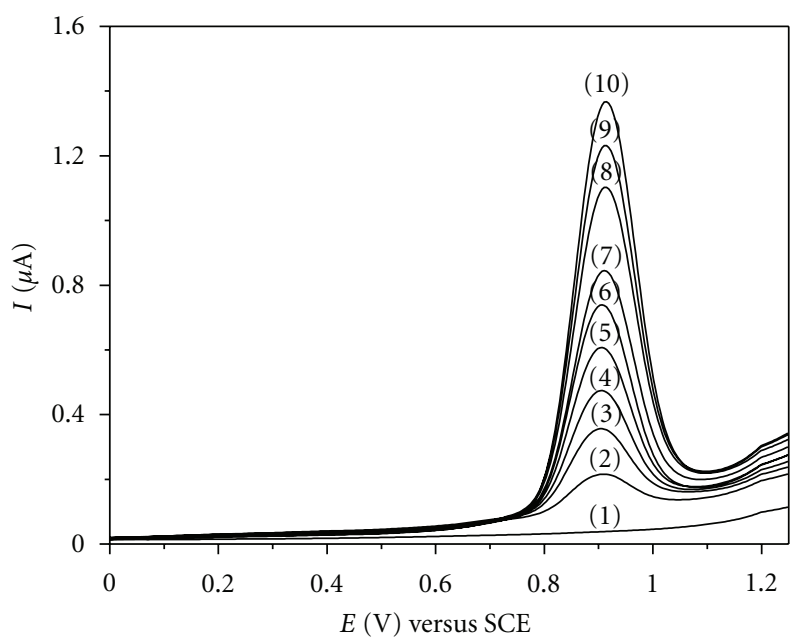

Figure 3: Differential Pulse Voltammograms. Effect of ASA concentration: (1) supporting electrolyte, (2) $0.01 \mathrm{mM}$, (3) $0.02 \mathrm{mM}$, (4) $0.03 \mathrm{mM}$, (5) $0.04 \mathrm{mM}$, (6) $0.05 \mathrm{mM}$, (7) $0.06 \mathrm{mM}$, (8) $0.08 \mathrm{mM}$, (9) $0.09 \mathrm{mM},(10) 0.1 \mathrm{mM}$; supporting electrolyte: $0.1 \mathrm{M} \mathrm{Na}_{2} \mathrm{SO}_{4} \mathrm{pH} 7$.

solution, constituted, as already mentioned, a basis for the chronoamperometric study of ASA electrochemical behavior at the same working electrode.

The detailed investigation using the chronoamperometry (CA) method, similar to our former study [57] at a fixed potential and sufficient time for a conventionally quasistationary state, was conducted to establish several working conditions and calibration plots data available as support for applications in practical analytical purposes, that is, the determination of ASA content in real samples obtained from pharmaceutical formulations.

Figure 5 shows a series of chronoamperograms regarding the effect of ASA concentration on the useful anodic response at unmodified BDDE, using standard solutions in $0.1 \mathrm{M}$ $\mathrm{Na}_{2} \mathrm{SO}_{4}$ (pH 7) supporting electrolyte.

The tested analyte was added in increasing concentration, from $0.01 \mathrm{mM}$ to $0.09 \mathrm{mM}$, and chronoamperograms were recorded at one potential level, $+0.9 \mathrm{~V}$ versus SCE, which corresponded to optimum ASA anodic amperometric signal. Calibration plot of anodic currents read at $120 \mathrm{~s}$ (a sufficient time period for obtaining a conventional steady state) versus ASA concentration (see Table 1) was linear, presenting a very good determination parameter $\left(R^{2}=0.997\right)$ and a satisfactory sensitivity value $\left(5.68 \mu \mathrm{A} \mathrm{mM}^{-1}\right)$. Under these conditions 


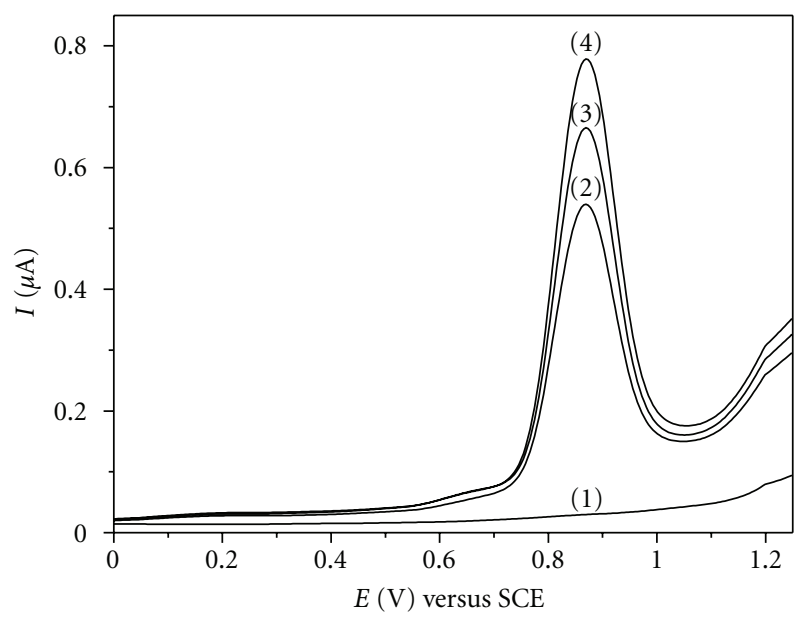

(a)

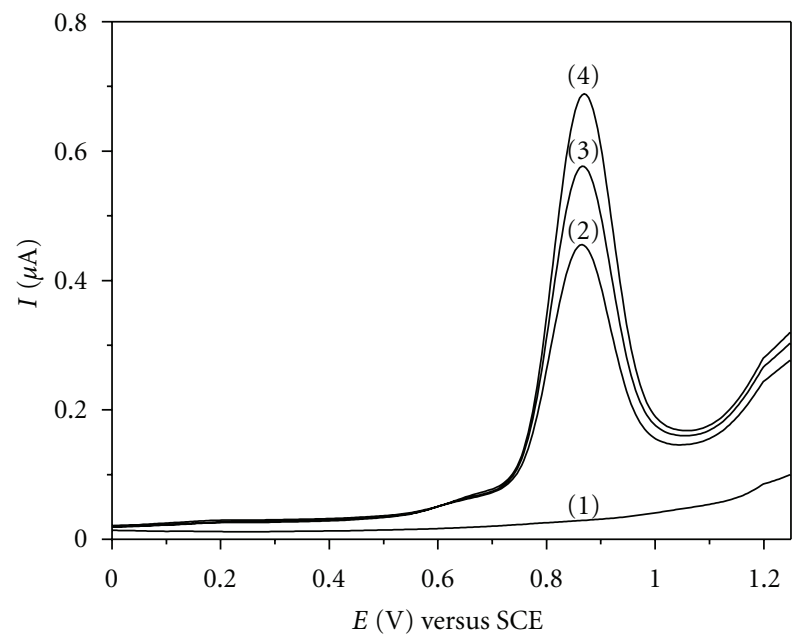

(b)

Figure 4: (a) Differential pulse voltammograms. (1) supporting electrolyte; (2) 0.2/50 dilution of Aspirin initial solution in supporting electrolyte; (3) 0.2/50 dilution of Aspirin initial solution in supporting electrolyte and ASA addition, $0.01 \mathrm{mM}$ ASA final supplementary concentration; (4) 0.2/50 dilution of Aspirin initial solution in supporting electrolyte and ASA addition, $0.02 \mathrm{mM}$ ASA final supplementary concentration; supporting electrolyte: $0.1 \mathrm{M} \mathrm{Na}_{2} \mathrm{SO}_{4} \mathrm{pH}$ 7. (b) Differential pulse voltammograms. (1) supporting electrolyte; (2) $0.2 / 50$ dilution of Acid Acetilsalicilic initial solution in supporting electrolyte; (3) 0.2/50 dilution of Acid Acetilsalicilic initial solution in supporting electrolyte and ASA addition, $0.01 \mathrm{mM}$ ASA final supplementary concentration; (4) 0.2/50 dilution of Acid Acetilsalicilic initial solution in supporting electrolyte and ASA addition, $0.02 \mathrm{mM}$ ASA final supplementary concentration; supporting electrolyte: $0.1 \mathrm{M} \mathrm{Na}_{2} \mathrm{SO}_{4} \mathrm{pH} 7$.

and according to $3 \sigma /$ slope criterion, the calculated LOD was $1.03 \mu \mathrm{M}$.

A continuous chronoamperogram (see Figure 6) recorded at one potential level, $+0.9 \mathrm{~V}$ versus SCE, and over the concentration range of $0.01 \mathrm{mM}-0.08 \mathrm{mM}$, was obtained under the conditions of progressive addition, in a stepwise fashion, of an ASA standard solution to the stirred solution of

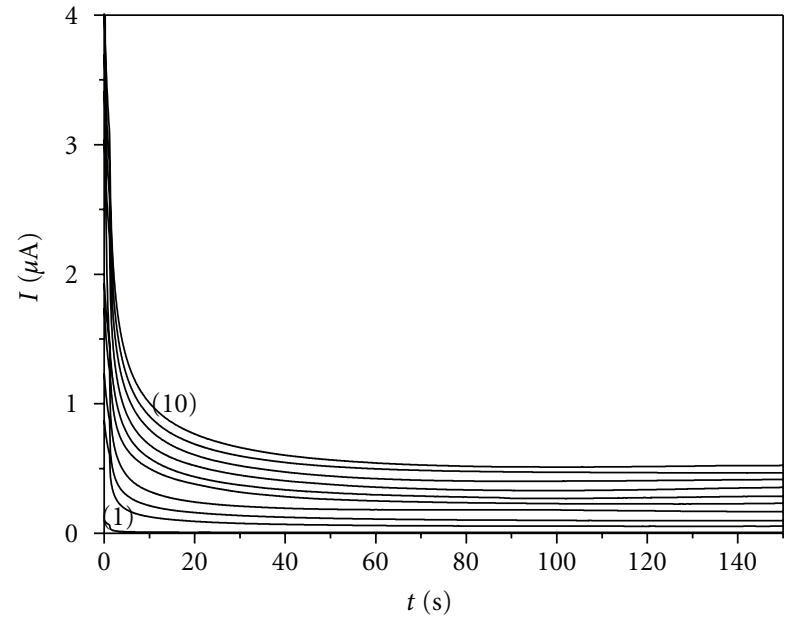

Figure 5: Chronoamperograms. Effect of ASA concentration at one potential level, $+0.9 \mathrm{~V}$ versus SCE, around the corresponding current peak potential from CVs. (1) supporting electrolyte, (2) $0.01 \mathrm{mM}$, (3) $0.02 \mathrm{mM}$, (4) $0.03 \mathrm{mM}$, (5) $0.04 \mathrm{mM}$, (6) $0.05 \mathrm{mM}$, (7) $0.06 \mathrm{mM}$, (8) $0.07 \mathrm{mM}$, (9) $0.08 \mathrm{mM}$, (10) $0.09 \mathrm{mM}$; supporting electrolyte: $0.1 \mathrm{M} \mathrm{Na}_{2} \mathrm{SO}_{4} \mathrm{pH} 7$.

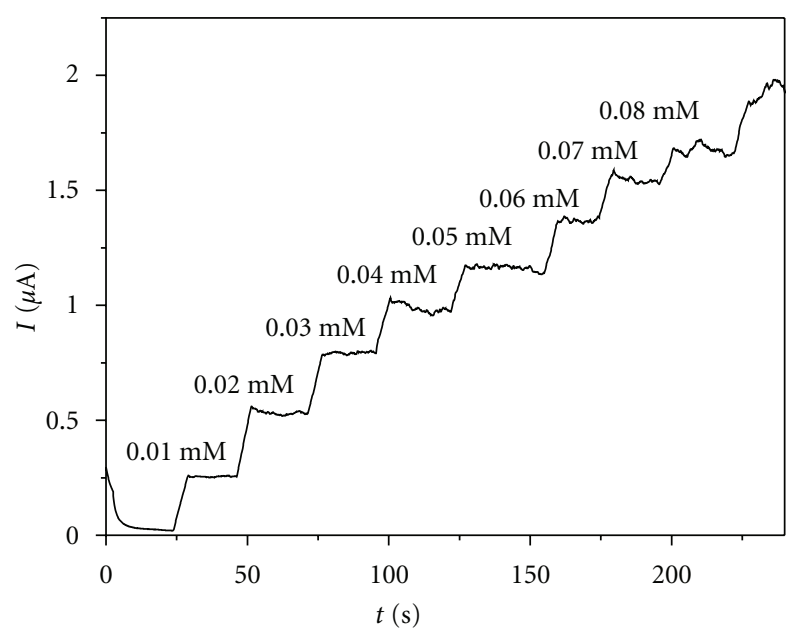

Figure 6: Continuous chronoamperogram at one potential level, $+0.9 \mathrm{~V}$ versus SCE, around the corresponding current peak potential from CVs; progressive addition of ASA in the concentration range of $0.01 \mathrm{mM}-0.08 \mathrm{mM}$; supporting electrolyte: $0.1 \mathrm{M} \mathrm{Na}_{2} \mathrm{SO}_{4}$ $\mathrm{pH} 7$; stirred solution.

0.1 $\mathrm{M} \mathrm{Na}_{2} \mathrm{SO}_{4}$ supporting electrolyte. No fouling of electrode surface occurred over the above-mentioned concentration range, characteristic aspect which suggested the further application of a BDD electrode as sensor for continuous ASA determination.

Linear plot (for calibration data, see also Table 1) of anodic currents read at 25 s, 50 s, 75 s, ..., and 225 s, respectively, versus ASA concentration presented a high sensitivity of $21.397 \mu \mathrm{A} \mathrm{mM}^{-1}$ and a very good determination coefficient $\left(R^{2}=0.998\right)$, and a $1.08 \mu \mathrm{M}$ LOD value was determined. 


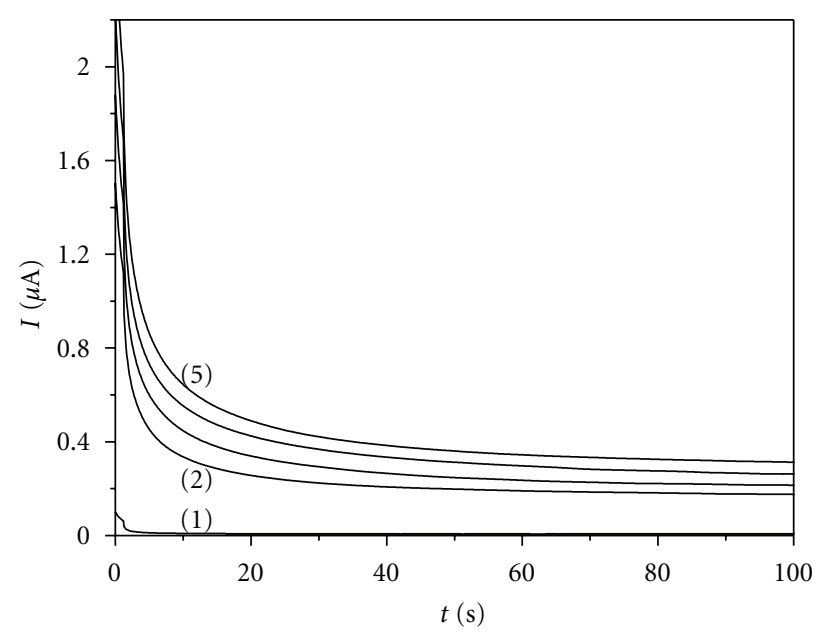

(a)

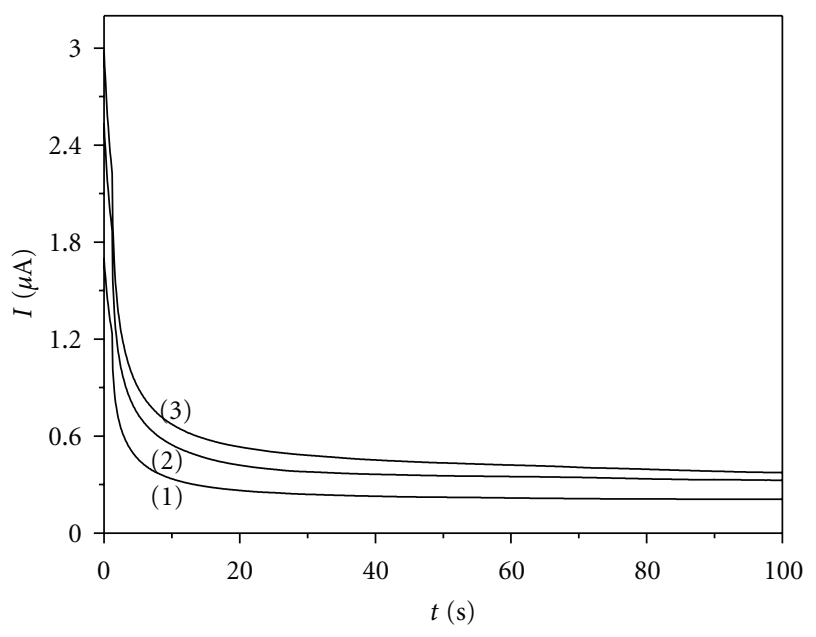

(b)

FIGURE 7: (a) Chronoamperograms, at one potential level, +0.9 V versus SCE. (1) supporting electrolyte; (2) 0.2/50 dilution of Aspirin initial solution in supporting electrolyte; (3) 0.2/50 dilution of Aspirin initial solution in supporting electrolyte and ASA addition, $0.01 \mathrm{mM}$ ASA final supplementary concentration; (4) 0.2/50 dilution of Aspirin initial solution in supporting electrolyte and ASA addition, $0.02 \mathrm{mM}$ ASA final supplementary concentration; (5) 0.2/50 dilution of Aspirin initial solution in supporting electrolyte and ASA addition, 0.03 mM ASA final supplementary concentration; supporting electrolyte: $0.1 \mathrm{M} \mathrm{Na}_{2} \mathrm{SO}_{4} \mathrm{pH} 7$; currents read at 100 s. (b) Chronoamperograms, at one potential level, $+0.9 \mathrm{~V}$ versus SCE. (1) $0.2 / 50$ dilution of Acid Acetilsalicilic initial solution in supporting electrolyte; (2) $0.2 / 50$ dilution of Acid Acetilsalicilic initial solution in supporting electrolyte and ASA addition, $0.02 \mathrm{mM}$ ASA final supplementary concentration; (3) 0.2/50 dilution of Acid Acetilsalicilic initial solution in supporting electrolyte and ASA addition, 0.03 mM ASA final supplementary concentration; supporting electrolyte: $0.1 \mathrm{M} \mathrm{Na}_{2} \mathrm{SO}_{4} \mathrm{pH}$ 7; currents read at $100 \mathrm{~s}$.

The utility of chronoamperometric method for the assessment of ASA in single component systems was suggested by the relatively high sensitivities, RSD values between 2 and $3 \%$, and also by low values of limit of detection. Thus, the potential usefulness of the elaborated method was then verified by practical data of chronoamperometry associated with standard addition method obtained from ASA determination in real samples of Aspirin (BAYER) and Acid Acetilsalicilic (SICOMED).

Figure 7(a) illustrates an example of chronoamperograms recorded at one potential level, $+0.9 \mathrm{~V}$ versus SCE, for a real sample of Aspirin, and for the mixture of real sample with ASA standard solution added to ensure $0.01 \mathrm{mM}$, $0.02 \mathrm{mM}$, and $0.03 \mathrm{mM}$ ASA final supplementary concentrantions in the system. In order to prepare the aqueous solution of real sample, a $0.5954 \mathrm{~g}$ Aspirin tablet was used according to the protocol described in the experimental section. A $0.2 \mathrm{~mL}$ Aspirin initial solution diluted to $50 \mathrm{~mL}$ volume with supporting electrolyte constituted the final volume of the real sample. Using CA technique coupled with standard addition method, the ASA average content in Aspirin real sample was $494.4 \mathrm{mg} /$ tablet. It should be noted that the $491.7 \mathrm{mg}$ ASA per tablet represented the average content determined when 5 Aspirin tablets with an average weight of $0.5951 \mathrm{~g}$ were investigated. According to the BAYER product specification, one Aspirin tablet contains $500 \mathrm{mg}$ acetylsalicylic acid.

The other example of ASA determination in pharmaceutical formulations refers to using of an Acid Acetilsalicilic (SICOMED) aqueous solution. The initial solution of real sample was prepared by solubilization of a $0.5847 \mathrm{~g}$ Acid Acetilsalicilic tablet using the volume control regime described in the experimental part. The real sample solution resulted from $0.2 \mathrm{~mL}$ Acid Acetilsalicilic initial solution diluted to $50 \mathrm{~mL}$ final volume with sodium sulphate supporting electrolyte (0.2/50 dilution). Very small volumes corresponding to final concentrations of $0.02 \mathrm{mM}$ and $0.03 \mathrm{mM}$ ASA standard solutions were added in the real sample and chronoamperograms at the same one potential level, $+0.9 \mathrm{~V}$ versus SCE, were recorded (see Figure $7(\mathrm{~b})$ ). Thus, for the chosen example, the determined average content was $467.9 \mathrm{mg}$ ASA/tablet. ASA content value in Acid Acetilsalicilic tablets indicated by the SICOMED supplier was $500 \mathrm{mg}$ ASA per tablet. The investigation of 5 Acid Acetilsalicilic tablets with an average weight of $0.5842 \mathrm{~g}$ gave an average content of $466.3 \mathrm{mg}$ ASA/tablet.

The association of differential pulse voltammetry, and chronoamperometry techniques with standard addition method proved to be very useful in analytical evaluation of both ASA-containing pharmaceutical products, Aspirin (BAYER) and Acid Acetilsalicilic (SICOMED). The matrix effects which can be attributed to the presence of adjacent inactive ingredients in pharmaceutical formulations were relatively minor and did not significantly perturb ASA determination. The average analytical data obtained for both pharmaceutical preparations corresponded to very good degrees of component recovery.

Linear calibration data and LOD values obtained are summarized in Table 1. 


\section{Conclusions}

The detection and determination of acetylsalicylic acid by differential pulse voltammetry and chronoamperometry using a mildly oxidized boron-doped diamond electrode and an easily accessible, simple unbuffered sodium sulphate solution as supporting electrolyte has been achieved.

Very good linearities of the calibration plots of anodic current peaks and anodic currents, respectively, versus ASA concentration resulted from DPV and CA data. Adjacent analytical data regarding RSD, LOD, and sensitivities were obtained.

The association of differential pulse voltammetric and chronoamperometric methods with standard addition method has been successfully used for a fast analytical evaluation of pharmaceutical formulations which contain acetylsalicylic acid without significant matrix effects. The average content of ASA in BAYER and SICOMED tablets, explored as real samples, was measured in good accordance with those indicated by the suppliers.

\section{References}

[1] Y. Ding and C. D. Garcia, "Determination of nonsteroidal anti-inflammatory drugs in serum by microchip capillary electrophoresis with electrochemical detection," Electroanalysis, vol. 18, no. 22, pp. 2202-2209, 2006.

[2] M. Farré, M. Petrovic, and D. Barceló, "Recently developed GC/MS and LC/MS methods for determining NSAIDs in water samples," Analytical and Bioanalytical Chemistry, vol. 387, no. 4, pp. 1203-1214, 2007.

[3] I. Farinelli and P. Martelletti, "Aspirin and tension-type headache," Journal of Headache and Pain, vol. 8, no. 1, pp. 49$55,2007$.

[4] A. Battezzati, G. Fiorillo, A. Spadafranca, S. Bertoli, and G. Testolin, "Measurement of salicylic acid in human serum using stable isotope dilution and gas chromatography-mass spectrometry," Analytical Biochemistry, vol. 354, no. 2, pp. 274 278, 2006.

[5] M. J. Scotter, D. P. T. Roberts, L. A. Wilson, F. A. C. Howard, J. Davis, and N. Mansell, "Free salicylic acid and acetylsalicylic acid content of foods using gas chromatography-mass spectrometry," Food Chemistry, vol. 105, p. 273, 2007.

[6] L. Campanella, A. Bonanni, D. Bellantoni, G. Favero, and M. Tomassetti, "Comparison of fluorimetric, voltammetric and biosensor methods for the determination of total antioxidant capacity of drug products containing acetylsalicylic acid," Journal of Pharmaceutical and Biomedical Analysis, vol. 36, no. 1, pp. 91-99, 2004.

[7] A. Guerrero, J. A. González-Correa, M. M. Arrebola, J. MuñozMarín, F. Sánchez De La Cuesta, and J. P. De La Cruz, "Antioxidant effects of a single dose of acetylsalicylic acid and salicylic acid in rat brain slices subjected to oxygenglucose deprivation in relation with its antiplatelet effect," Neuroscience Letters, vol. 358, no. 3, pp. 153-156, 2004.

[8] G. Şener-MuratoGlu, K. PaskaloGlu, S. Arbak, C. HürdaG, and G. AyanoGlu-Dülger, "Protective effect of famotidine, omeprazole, and melatonin against acetylsalicylic acidinduced gastric damage in rats," Digestive Diseases and Sciences, vol. 46, no. 2, pp. 318-330, 2001.

[9] A. Polat and M. H. Emre, "Effects of melatonin or acetylsalicylic acid on gastric oxidative stress after bile duct ligation in rats," Journal of Gastroenterology, vol. 41, no. 5, pp. 433-439, 2006.

[10] J. A. Murillo Pulgarín, A. Alañón Molina, P. Fernández López, and I. Sánchez-Ferrer Robles, "Direct determination of closely overlapping drug mixtures of diflunisal and salicylic acid in serum by means of derivative matrix isopotential synchronous fluorescence spectrometry," Analytica Chimica Acta, vol. 583, no. 1, pp. 55-62, 2007.

[11] M. M. Karim, H. S. Lee, Y. S. Kim, H. S. Bae, and S. H. Lee, "Analysis of salicylic acid based on the fluorescence enhancement of the As(III)-salicylic acid system," Analytica Chimica Acta, vol. 576, no. 1, pp. 136-139, 2006.

[12] M. S. M. Quintino, D. Corbo, M. Bertotti, and L. Angnes, "Amperometric determination of acetylsalicylic acid in drugs by batch injection analysis at a copper electrode in alkaline solutions," Talanta, vol. 58, no. 5, pp. 943-949, 2002.

[13] A. V. Pereira, C. Aniceto, and O. Fatibello-Filho, "Flow injection spectrophotometric determination of acetylsalicylic acid in tablets after on-line microwave-assisted alkaline hydrolysis," Analyst, vol. 123, no. 5, pp. 1011-1015, 1998.

[14] J. M. García, A. I. Jiménez, F. Jiménez, and J. J. Arias, "Simultaneous determination of salicylamide, acetylsalicylic acid and salicylic acid by multi-wavelength spectrophotometric methods," Analytical Letters, vol. 29, no. 2, pp. 249-263, 1996.

[15] A. B. Moreira, I. L. T. Dias, G. O. Neto, E. A. G. Zagatto, and L. T. Kubota, "Solid-phase fluorescence spectroscopy for the determination of acetylsalicylic acid in powdered pharmaceutical samples," Analytica Chimica Acta, vol. 523, no. 1, pp. 49-52, 2004.

[16] M. M. Sena, M. G. Trevisan, and R. J. Poppi, "Combining standard addition method and second-order advantage for direct determination of salicylate in undiluted human plasma by spectrofluorimetry," Talanta, vol. 68, no. 5, pp. 1707-1712, 2006.

[17] S. O. Algar, N. R. Martos, and A. M. Díaz, "Fast and single solid phase fluorescence spectroscopic batch procedure for (acetyl) salicylic acid determination in drug formulations," Journal of Pharmaceutical and Biomedical Analysis, vol. 31, no. 3, pp. 439-446, 2003.

[18] A. Ruiz-Medina, M. L. Fernández-de Córdova, P. OrtegaBarrales, and A. Molina-Díaz, "Flow-through UV spectrophotometric sensor for determination of (acetyl)salicylic acid in pharmaceutical preparations," International Journal of Pharmaceutics, vol. 216, no. 1-2, pp. 95-104, 2001.

[19] E. Mikami, T. Goto, T. Ohno, H. Matsumoto, and M. Nishida, "Simultaneous analysis of dehydroacetic acid, benzoic acid, sorbic acid and salicylic acid in cosmetic products by solidphase extraction and high-performance liquid chromatography," Journal of Pharmaceutical and Biomedical Analysis, vol. 28, no. 2, pp. 261-267, 2002.

[20] Z. Kokot and K. Burda, "Simultaneous determination of salicylic acid and acetylsalicylic acid in aspirin delayed-release tablet formulations by second-derivative UV spectrophotometry," Journal of Pharmaceutical and Biomedical Analysis, vol. 18, no. 4-5, pp. 871-875, 1998.

[21] M. M. Karim, C. W. Jeon, H. S. Lee et al., "Simultaneous determination of acetylsalicylic acid and caffeine in pharmaceutical formulation by first derivative synchronous fluorimetric method," Journal of Fluorescence, vol. 16, no. 5, pp. 713-721, 2006.

[22] Z. Bouhsain, S. Garrigues, and M. De La Guardia, "PLSUV spectrophotometric method for the simultaneous determination of paracetamol, acetylsalicylic acid and caffeine in 
pharmaceutical formulations," Fresenius' Journal of Analytical Chemistry, vol. 357, no. 7, pp. 973-976, 1997.

[23] A. Navalón, R. Blanc, M. Del Olmo, and J. L. Vilchez, "Simultaneous determination of naproxen, salicylic acid and acetylsalicylic acid by spectrofluorimetry using partial leastsquares (PLS) multivariate calibration," Talanta, vol. 48, no. 2 , pp. 469-475, 1999.

[24] M. R. Gomez, R. A. Olsina, L. D. Martínez, and M. F. Silva, "Simultaneous determination of cloramphenicol, salicylic acid and resorcinol by capillary zone electrophoresis and its application to pharmaceutical dosage forms," Talanta, vol. 61, no. 2, pp. 233-238, 2003.

[25] M. L. Altun, T. Ceyhan, M. Kartal, T. Atay, N. Ozdemir, and S. CevheroGlu, "LC method for the analysis of acetylsalicylic acid, caffeine and codeine phosphate in pharmaceutical preparations," Journal of Pharmaceutical and Biomedical Analysis, vol. 25, no. 1, pp. 93-101, 2001.

[26] S. T. Eberhart, A. Hatzis, and R. Rothchild, "Quantitative NMR assay for aspirin, phenacetin, and caffeine mixtures with 1,3,5-trioxane as internal standard," Journal of Pharmaceutical and Biomedical Analysis, vol. 4, no. 2, pp. 147-154, 1986.

[27] E. R. Montgomery, S. Taylor, J. Segretario, E. Engler, and D. Sebastian, "Development and validation of a reversedphase liquid chromatographic method for analysis of aspirin and warfarin in a combination tablet formulation," Journal of Pharmaceutical and Biomedical Analysis, vol. 15, no. 1, pp. 7382, 1996.

[28] F. A. El-Yazbi, H. H. Hammud, and S. A. Assi, "Derivativeratio spectrophotometric method for the determination of ternary mixture of aspirin, paracetamol and salicylic acid," Spectrochimica Acta. Part A, vol. 68, no. 2, pp. 275-278, 2007.

[29] V. Pucci, R. Mandrioli, M. A. Raggi, and S. Fanali, "Reversedphase capillary electrochromatography for the simultaneous determination of acetylsalicylic acid, paracetamol, and caffeine in analgesic tablets," Electrophoresis, vol. 25, no. 4-5, pp. 615-621, 2004.

[30] V. Supalkova, J. Petrek, L. Havel et al., "Electrochemical sensors for detection of acetylsalicylic acid," Sensors, vol. 6, no. 11, pp. 1483-1497, 2006.

[31] K. Selinger and W. C. Purdy, "The determination of salicylic acid and its metabolites in blood plasma by high-performance liquid chromatography with amperometric detection," Analytica Chimica Acta, vol. 149, pp. 343-347, 1983.

[32] J. M. P. J. Garrido, J. L. F. C. Lima, and C. D. Matos, "Flow injection determination of acetylsalicylic acid in pharmaceutical preparations with an amperometric detector," Collection of Czechoslovak Chemical Communications, vol. 65, no. 6, pp. 954-962, 2000.

[33] A. A. J. Torriero, J. M. Luco, L. Sereno, and J. Raba, "Voltammetric determination of salicylic acid in pharmaceuticals formulations of acetylsalicylic acid," Talanta, vol. 62, no. 2, pp. 247-254, 2004.

[34] B. Louhichi, N. Bensalash, and A. Gadri, "Electrochemical oxidation of benzoic acid derivatives on boron doped diamond: voltammetric study and galvanostatic electrolyses," Chemical Engineering and Technology, vol. 29, no. 8, pp. 944-950, 2006.

[35] F. Montilla, P. A. Michaud, E. Morallón, J. L. Vázquez, and C. Comninellis, "Electrochemical oxidation of benzoic acid at boron-doped diamond electrodes," Electrochimica Acta, vol. 47, no. 21, pp. 3509-3513, 2002.

[36] D. Evans, J. P. Hart, and G. Rees, "Voltammetric behaviour of salicylic acid at a glassy carbon electrode and its determination in serum using liquid chromatography with amperometric detection," Analyst, vol. 116, no. 8, pp. 803-806, 1991.
[37] Y. S. Fung and S. F. Luk, "Determination of salicylic acid in pharmaceutical formulations and foods by differentialpulse voltammetry using a glassy carbon electrode," Analyst, vol. 114, no. 8, pp. 943-945, 1989.

[38] J. C. B. Fernandes, C. A. B. Garcia, L. A. Grandin, G. De Oliveira Neto, and O. E. S. Godinho, "Determination of acetylsalicylic acid in tablets with salicylate ion selective electrode in a batch injection analysis system," Journal of the Brazilian Chemical Society, vol. 9, no. 3, pp. 249-251, 1998.

[39] B. Muralidharan, G. Gopu, C. Vedhi, and P. Manisankar, "Voltammetric determination of analgesics using a montmorillonite modified electrode," Applied Clay Science, vol. 42, no. 1-2, pp. 206-213, 2008.

[40] B. G. Milagres, G. De Oliveira Neto, L. T. Kubota, and H. Yamanaka, "A new amperometric biosensor for salicylate based on salicylate hydroxylase immobilized on polipyrrole film doped with hexacyanoferrate," Analytica Chimica Acta, vol. 347, no. 1-2, pp. 35-41, 1997.

[41] H. Paseková, M. G. Sales, M. C. Montenegro, A. N. Araújo, and M. Polášek, "Potentiometric determination of acetylsalicylic acid by sequential injection analysis (SIA) using a tubular salicylate-selective electrode," Journal of Pharmaceutical and Biomedical Analysis, vol. 24, no. 5-6, pp. 1027-1036, 2001.

[42] V. J. F. Ferreira, A. C. V. Cavalheiro, E. Fagnani et al., "An electrode of the second kind for aspirin determination in tablet formulations," Analytical Sciences, vol. 15, no. 3, pp. 249-253, 1999.

[43] M. Neumayr, O. Friedrich, G. Sontag, and F. Pittner, "Flowinjection analysis with electrochemical detection for determination of salicylic acid in pharmaceutical preparations," Analytica Chimica Acta, vol. 273, no. 1-2, pp. 469-475, 1993.

[44] S. Majdi, A. Jabbari, and H. Heli, "A study of the electrocatalytic oxidation of aspirin on a nickel hydroxide-modified nickel electrode," Journal of Solid State Electrochemistry, vol. 11, no. 5, pp. 601-607, 2007.

[45] E. Guinea, C. Arias, P. L. Cabot et al., "Mineralization of salicylic acid in acidic aqueous medium by electrochemical advanced oxidation processes using platinum and borondoped diamond as anode and cathodically generated hydrogen peroxide," Water Research, vol. 42, no. 1-2, pp. 499-511, 2008.

[46] C. Batchelor-McAuley and G. G. Wildgoose, "The influence of substrate effects when investigating new nanoparticle modified electrodes exemplified by the electroanalytical determination of aspirin on $\mathrm{NiO}$ nanoparticles supported on graphite," Electrochemistry Communications, vol. 10, no. 8, pp. 1129-1131, 2008.

[47] M. Houshmand, A. Jabbari, H. Heli, M. Hajjizadeh, and A. A. Moosavi-Movahedi, "Electrocatalytic oxidation of aspirin and acetaminophen on a cobalt hydroxide nanoparticles modified glassy carbon electrode," Journal of Solid State Electrochemistry, vol. 12, no. 9, pp. 1117-1128, 2008.

[48] E. R. Sartori, R. A. Medeiros, R. C. Rocha-Filho, and O. Fatibello-Filho, "Square-wave voltammetric determination of acetylsalicylic acid in pharmaceutical formulations using a boron-doped diamond electrode without the need of previous alkaline hydrolysis step," Journal of the Brazilian Chemical Society, vol. 20, no. 2, pp. 360-366, 2009.

[49] S. E. Coe and R. S. Sussmann, "Optical, thermal and mechanical properties of CVD diamond," Diamond and Related Materials, vol. 9, no. 9-10, pp. 1726-1729, 2000.

[50] M. Witek, J. Wang, J. Stotter et al., "Summary of recent progress with diamond electrodes in electroanalysis, spectroelectrochemistry and electrocatalysis," Journal of Wide Bandgap Materials, vol. 8, no. 3-4, pp. 171-188, 2001. 
[51] Y. V. Pleskov, "Electrochemistry of diamond," Russian Journal of Electrochemistry, vol. 38, no. 12, pp. 1275-1291, 2002.

[52] M. C. Granger, J. Xu, J. W. Strojek, and G. M. Swain, "Polycrystalline diamond electrodes: basic properties and applications as amperometric detectors in flow injection analysis and liquid chromatography," Analytica Chimica Acta, vol. 397, no. 1-3, pp. 145-161, 1999.

[53] R. G. Compton, J. S. Foord, and F. Marken, "Electroanalysis at diamond-like and doped-diamond electrodes," Electroanalysis, vol. 15, no. 17, pp. 1349-1363, 2003.

[54] A. Kraft, "Doped diamond: a compact review on a versatile electrode material," International Journal of Electrochemcal Science, vol. 2, p. 355, 2007.

[55] C. Radovan and F. Manea, "Determination of sodium diethyldithiocarbamate in water by anodic voltammetry using a boron-doped diamond electrode," Electroanalysis, vol. 19, no. 1, pp. 91-95, 2007.

[56] C. Radovan, C. Cofan, and D. Cinghiţă, "Simultaneous determination of acetaminophen and ascorbic acid at an unmodified boron-doped diamond electrode by differential pulse voltammetry in buffered media," Electroanalysis, vol. 20, no. 12, pp. 1346-1353, 2008.

[57] C. Cofan and C. Radovan, "Simultaneous chronoamperometric sensing of ascorbic acid and acetaminophen at a borondoped diamond electrode," Sensors, vol. 8, no. 6, pp. 39523969, 2008.

[58] C. Radovan, D. Cinghiţă, F. Manea, M. Mincea, C. Cofan, and V. Ostafe, "Electrochemical sensing and assessment of parabens in hydro-alcoholic solutions and water using a boron-doped diamond electrode," Sensors, vol. 8, no. 7, pp. 4330-4349, 2008.

[59] C. Cofan, C. Radovan, and D. Cinghiță, "Simultaneous anodic assessment of ascorbic acid and acetaminophen in unbuffered solutions," Revista de Chimie, vol. 60, no. 4, pp. 368-372, 2009. 


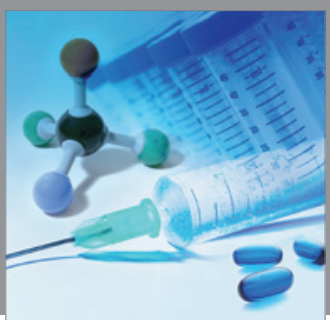

International Journal of

Medicinal Chemistry

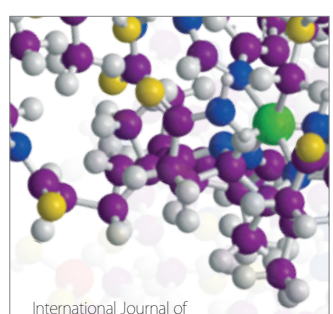

Carbohydrate Chemistry

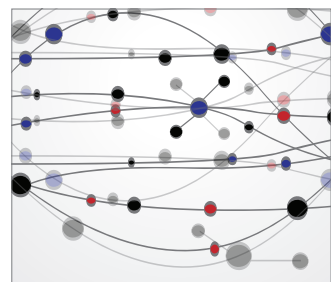

The Scientific World Journal
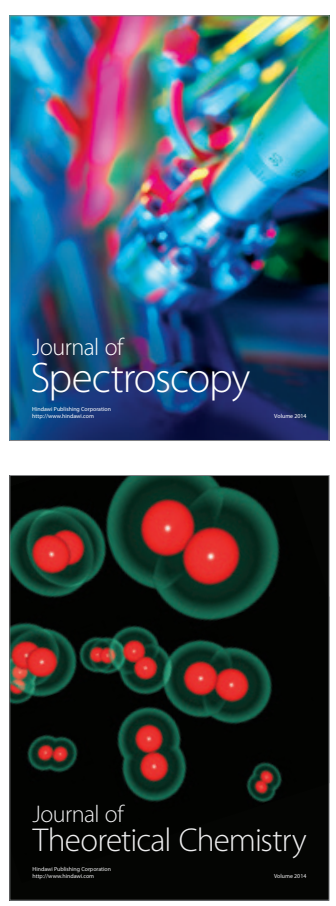
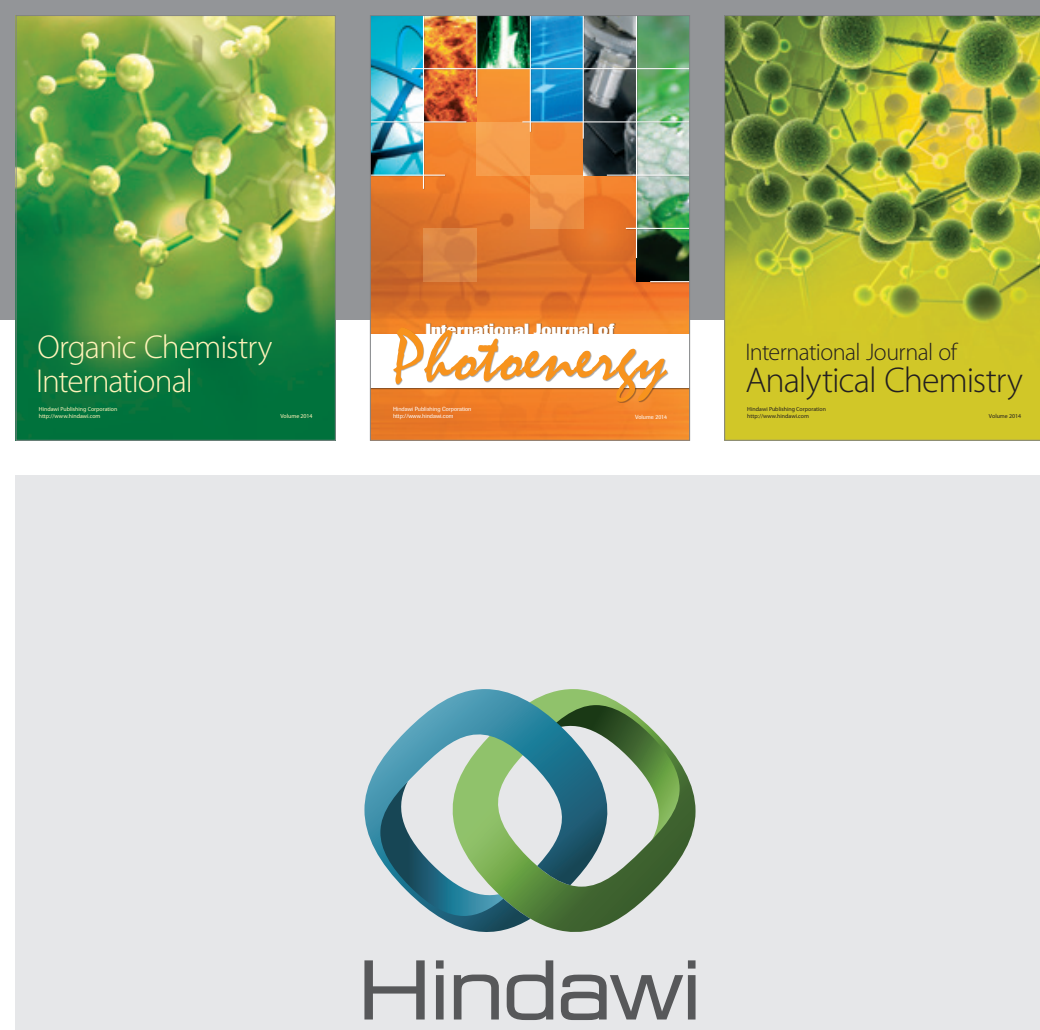

Submit your manuscripts at

http://www.hindawi.com
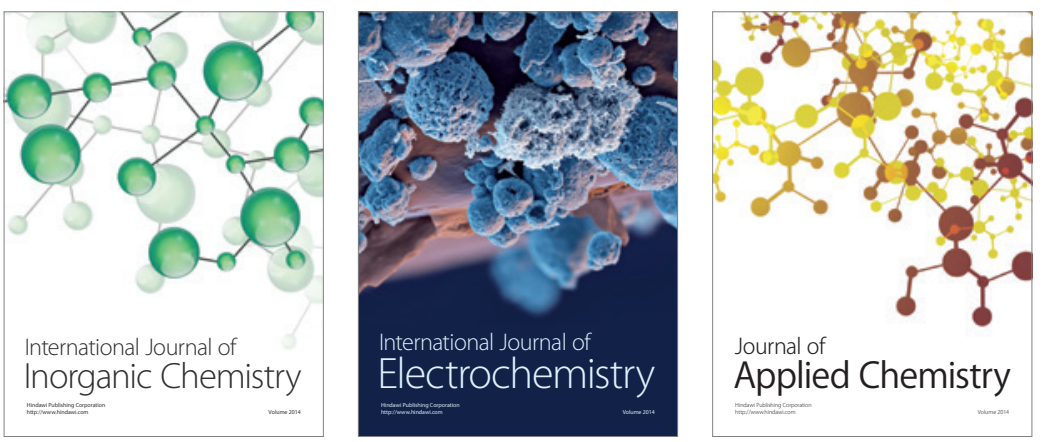

Journal of

Applied Chemistry
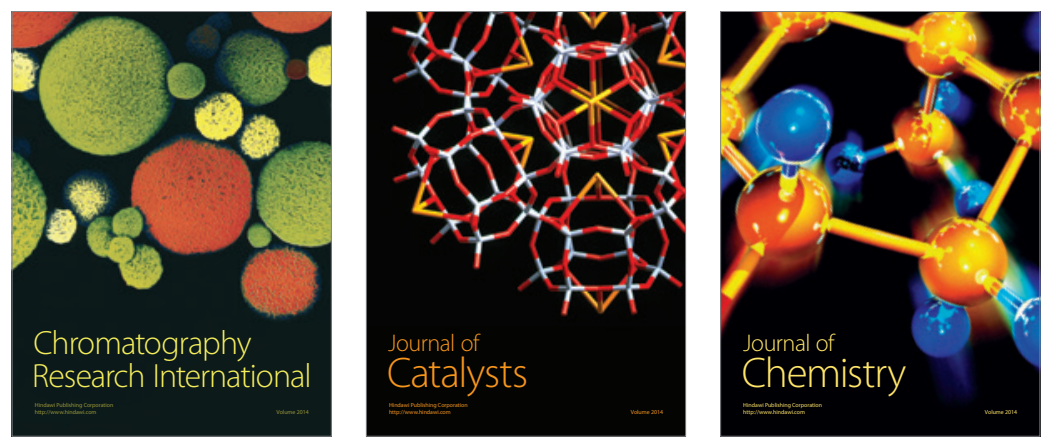
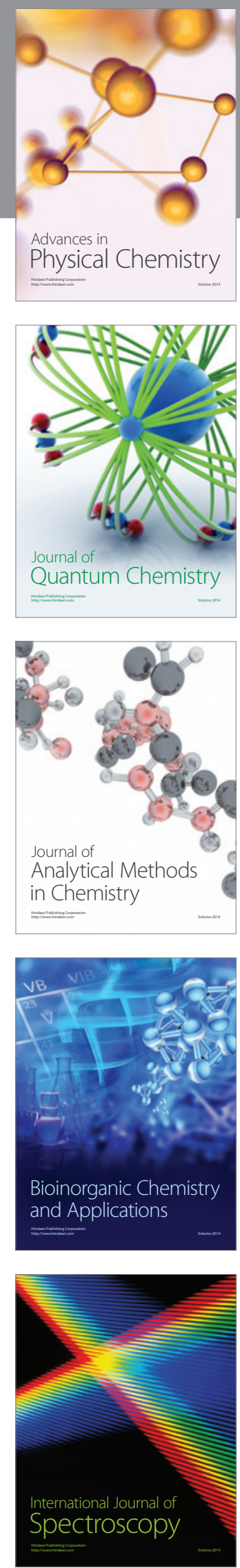